\title{
Research on Cumulative Damage Characteristics of Rock Anchor Beam Concrete Supporting Structure by Blasting Vibration of Underground Powerhouse
}

\author{
Sheng Wan $\mathbb{D}^{1,2}$ Junhong Huang $\mathbb{D}^{1,3,4}{ }^{1,4}$ Yi Luo $\mathbb{D}^{1},{ }^{1}$ Xinping Li $\mathbb{D}^{1},{ }^{1}$ and Qingsong Pu $\mathbb{D}^{1,2}$ \\ ${ }^{1}$ Hubei Key Laboratory of Roadway Bridge and Structure, Wuhan University of Technology, Wuhan, China \\ ${ }^{2}$ School of Civil Engineering and Architecture, Wuhan University of Technology, Wuhan, China \\ ${ }^{3}$ School of Safety Science and Emergency Management, Wuhan University of Technology, Wuhan, China \\ ${ }^{4}$ School of Resource, Environmental Science and Engineering, Hubei University of Science and Technology, Xianning, China
}

Correspondence should be addressed to Junhong Huang; junhonghuang@whut.edu.cn

Received 4 May 2020; Revised 29 May 2020; Accepted 14 March 2021; Published 24 March 2021

Academic Editor: Xue-qiu He

Copyright (C) 2021 Sheng Wan et al. This is an open access article distributed under the Creative Commons Attribution License, which permits unrestricted use, distribution, and reproduction in any medium, provided the original work is properly cited.

\begin{abstract}
Aiming at the dynamic disturbance problem of the upper rock anchor beam concrete support structure caused by the blasting excavation of the lower rock mass of the underground powerhouse of the hydropower station, the dynamic finite element software was used to numerically simulate the cumulative damage characteristics of the rock anchor beam concrete structure under multiple blasting, which aims to study the effect of blasting times and blast center distance on the cumulative damage characteristics of rock anchor beam concrete structures in two directions at different ages. The results show that 7 days after the completion of the concrete pouring of rock anchor beam, the damage and destruction effects are produced under the single blasting action. 28 days after the completion of the concrete pouring, there is basically no damage and destruction under the action of five times of blasting. 14 days after the completion of the concrete pouring, the growth process of the cumulative damage effect of the rock anchor beam concrete structure under the disturbance of the blasting excavation of the underground powerhouse shows nonlinear increasing characteristics with the increase of blasting times and nonlinear decreasing characteristics with the increase of blasting center distance. The cumulative damage of rock anchor beam along and perpendicular to the axis of powerhouse conforms to the relationship of cubic polynomials with the blasting times, which also conform to the relationship of quartic polynomial and quadratic polynomial, respectively, with the blast center distance.
\end{abstract}

\section{Introduction}

In the layout of underground powerhouses of modern hydropower stations, especially pumped storage power stations, rock anchor crane beam structures are mostly used $[1-3]$. Because it undertakes the operation function of the crane in the powerhouse, it belongs to the core control object in structural design and construction. As the pouring of rock anchor beam is often carried out at the same time with the layered excavation of the powerhouse [4], if the blasting construction is not properly controlled, the concrete cracking of rock anchor beam caused by blasting vibration, and the loss of bond force between concrete and rock will have adverse effects on the later safe operation of rock anchor beam $[5,6]$.

Frequent and repeated blasting will cause cumulative damage to surrounding rock and concrete supporting structure, reducing the physical and mechanical properties and durability of the structure. When the damage accumulates to a certain extent, it may lead to local or even overall instability of the structure, seriously affecting the efficiency and economy of the engineering construction [7-10]. Ramulu et al. [11] pointed out that repeated blasting loading during excavation will accelerate the development of damage area of surrounding rock. The research shows that the process of the cumulative damage leading to the 
macrofailure of engineering rock mass is caused by repeated blasting disturbance. It is of great significance to carry out the experimental research on the cumulative damage degree of concrete structure blasting and the attenuation law of blasting vibration propagation.

In the aspect of damage research of blasting load on concrete supporting structure, Duan et al. [12] used wavelet packet analysis technology to calculate the energy value in different frequency band of vibration signal under different blasting conditions (blasting times and blasting center distance) and discussed the influence rule of different blasting conditions on energy signal distribution. Liu et al. [13] obtained the change characteristics of the energy distribution law of each frequency band of the acoustic signal after the wavelet decomposition with the concrete damage degree. Liang et al. [14] believed that the overpressure of blast shock wave is the main factor of concrete damage, and the explosion gas has an important effect on the propagation of existing cracks and the generation of new cracks. Miao [15] found that when the radial uncoupling charge coefficient of the blasthole is greater than 3, the surrounding rock damage decreases rapidly under the effect of blasting load.

In regard to the propagation law of blasting vibration in concrete structure, Zhang [16] proposed for the first time that the particle vibration speed of $7 \mathrm{~cm} / \mathrm{s}$ was taken as the blasting safety control standard of 28 days after the completion of concrete pouring of rock anchor beam. Yao et al. [17] believed that as the height difference increased, the particle vibration velocity of the high side wall gradually decreased and the maximum tensile stress appeared at the top or bottom of the rock anchor beam bonding surface, which has a good correlation with the horizontal particle vibration velocity. The maximum tensile stress and particle vibration velocity at the arch foot of the crown are relatively large, while the maximum tensile stress and particle vibration velocity above the arch foot decrease rapidly [18].

\section{Theoretical Analysis of Blasting Load}

2.1. Constitutive Model. The RHT constitutive model is selected, and the equation of state in the constitutive model RHT describes the relationship among hydrostatic pressure, material density, and internal energy. The equation of state after full compaction is as follows:

$$
\begin{aligned}
& P=A_{1} \mu+A_{2} \mu^{2}+A_{3} \mu^{3}+\left(B_{0}+B_{1} \mu\right) \rho_{0} e, \quad \mu>0, \\
& P=T_{1} \mu+T_{2} \mu^{2}+B_{0} \rho_{0} e, \quad \mu<0,
\end{aligned}
$$

where $\mu=\rho / \rho_{0}-1$. When $\mu>0$, the material is compressed, and when $\mu<0$, the material is stretched. $\rho_{0}$ is the density when the material is not stretched or compressed, $\rho$ is the real-time material density, and $e$ is the initial internal energy of the material. $A 1, A 2$, and $A 3$ are Hugoniot polynomial coefficients. $B 0, B 1, T 1$, and $T 2$ are the state equation parameters.

When there are pores in the material, the effect of porosity $\alpha$ should be taken into account. If the density of porous material is $\rho_{p}$, the density of material is $\rho_{p} \alpha$, and the corresponding equation of state is as follows:

$$
\begin{aligned}
& P=f(\rho \alpha, e), \\
& \alpha=1+\left(\alpha_{0}-1\right)\left[\frac{P_{\text {lock }}-P}{P_{\text {lock }}-P_{\text {crush }}}\right]^{n}, \\
& \alpha=\frac{\rho_{0}}{\rho_{p}}
\end{aligned}
$$

where $P_{\text {crush }}$ is the pressure when the pores in the material begin to be compressed $\left(\alpha=\alpha_{0}\right), P_{\text {lock }}$ is the pressure when the pores in the material completely disappear $(\alpha=1)$, and $n$ is the compression index.

The RHT constitutive model defines the elastic limit surface, failure surface, and residual strength surface to describe the strength change law of the material. They described the initial yield strength, failure strength, and residual strength of the material. Since the material is assumed to be isotropic, the elastic limit surface and failure surface under the triaxial load can be represented by a curved surface in a three-dimensional principal stress space, and it is triple symmetrical in the offplane. The relationship among the elastic limit surface, residual strength surface, and failure surface is shown in Figure 1.

In the process of plastic deformation in the elastic stage and the linear strengthening stage, there is no damage in the material. Only when the stress state of the material reaches the failure surface, that is, when the effective force exceeds the failure strength, can the material begin to enter the damage softening stage, resulting in damage and accumulation.

(a) Definition and evolution of damage variable The definition of the damage variable $D_{0}$ is

$$
\begin{aligned}
0 \leq D_{0} & =\sum \frac{\triangle \varepsilon_{p}}{\varepsilon_{p}^{\text {failure }}} \leq 1, \\
\varepsilon_{p}^{\text {failure }} & =D_{1}\left(P^{*}-H T L^{*}\right)^{D_{2}} \geq \varepsilon_{p}^{m},
\end{aligned}
$$

where $\Delta \varepsilon_{p}$ is the equivalent plastic strain increment, $D_{1}$ and $D_{2}$ are the parameters of the material, and $\varepsilon_{p}^{m}$ is the minimum equivalent plastic strain when the material is damaged.

(b) Residual equivalent stress intensity

After the material reaches the failure surface and accumulates a certain amount of damage, due to the effect of confining pressure, there is still some frictional bite force between the broken blocks, so that the material still has a certain shear resistance. For this reason, the residual stress surface is introduced into RHT constitutive, and its equivalent stress intensity is

$$
\sigma_{\text {residual }}=A_{f} \times\left(P^{*}\right)^{n_{f}} .
$$

Among them, $A_{f}$ is the residual stress intensity parameter, and $n_{f}$ is the residual stress intensity index. 


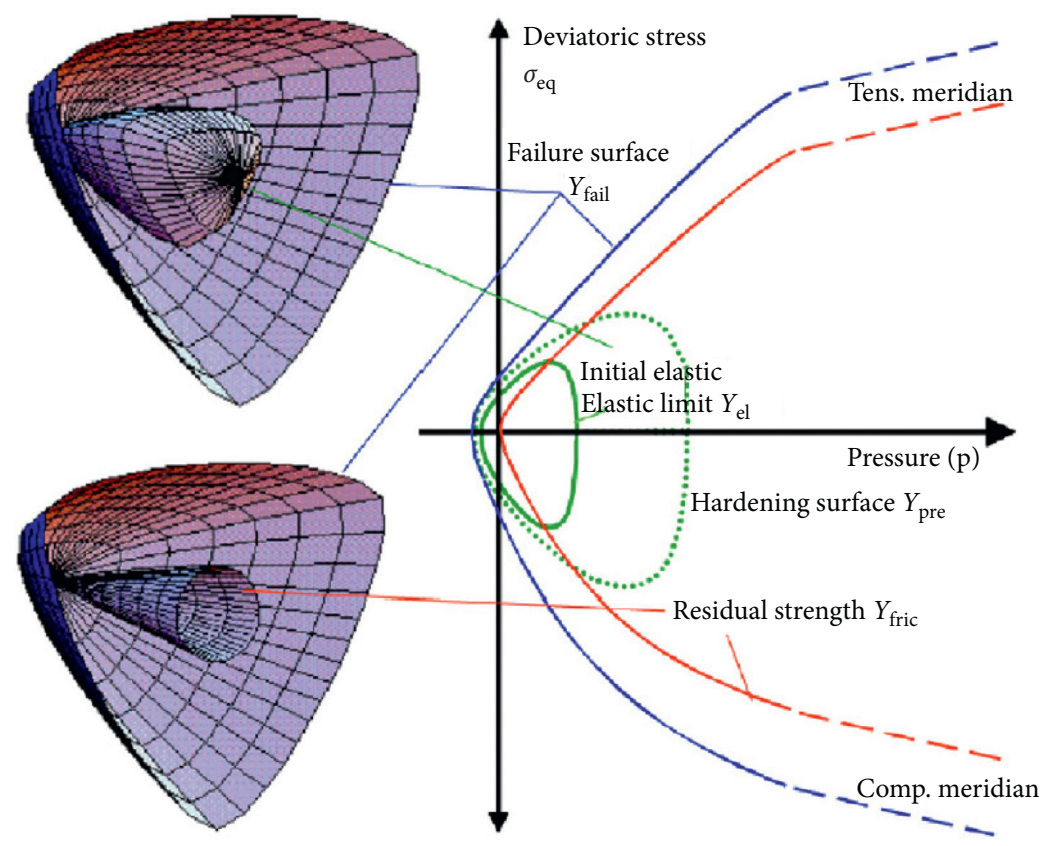

FIgURE 1: Schematic diagram of elastic limit surface, failure surface, and residual strength surface of the RHT model.

(c) Equivalent stress intensity at the damage stage after failure

After the stress state of the material reaches the failure surface, with the accumulation of material damage, the deviator stress in the material decreases gradually. Therefore, the equivalent stress intensity $\sigma_{\text {damage }}$ at the damage stage can be determined according to the interpolation of the damage value between the equivalent stress intensity at the failure surface and the residual equivalent stress intensity:

$$
\sigma_{\text {damage }}=\left(1-D_{0}\right) \sigma_{\text {failure }}+D_{0} \sigma_{\text {residual }} \text {. }
$$

2.2. Explosion Load. In this study, the simplified triangle explosion load curve is adopted for dynamic loading [19] as shown in Figure 2.

According to the C-J theory of the detonation wave of condensed explosive, for the caving hole, the charge uncoupling coefficient is small, and the pressure peak $P_{b}$ of the detonation gas acting on the wall of the blast hole is

$$
P_{b}=\frac{\rho_{e}(V)^{2}}{2(\gamma+1)}\left(\frac{d_{c}}{d_{b}}\right)^{2 \gamma}
$$

For buffer holes and smooth blasting holes, the uncoupling coefficient is large, and the expansion of gas needs to go through two stages: $P \geq P_{k}$ and $P<P_{k}$. $P_{k}$ is the critical pressure of explosion gas, taken as $200 \mathrm{MPa}$. In the calculation, the isentropic index is treated as a piecewise constant. When $P \geq P_{k}, \gamma=3.0$. When $P<P_{k}, \gamma=v=4 / 3$. Then, the above formula becomes

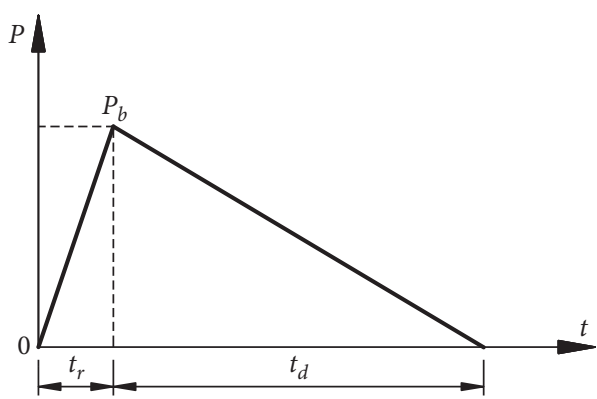

FIGURE 2: Time history curve of explosion pressure of equivalent triangle.

$$
P_{b}=\left[\frac{\rho_{e}(V)^{2}}{2(\gamma+1)}\right]^{\frac{\nu}{\gamma}} P_{k}^{(\gamma-v) / \gamma}\left(\frac{d_{c}}{d_{b}}\right)^{2 \gamma},
$$

where $\rho_{e}$ and $V$ are the explosive density and detonation velocity. $d_{c}$ is the charge diameter, and $d_{b}$ is the blast hole diameter. The load boosting action time is $t_{r}=0.2 \mathrm{~ms}$, and the positive pressure action time is $t_{d}=1.2 \mathrm{~ms}$. The explosive density is $\rho_{e}=1.0 \mathrm{~g} / \mathrm{cm}^{3}$, and detonation wave velocity is $V=3600 \mathrm{~m} / \mathrm{s}$.

The schematic diagram of the design hole layout of pilot tunnel blasting in the first floor of the underground powerhouse of Qingyuan pumped storage power station is shown in Figure 3. The interval time of blasting load in each section is controlled by the delay initiation time of detonator, as shown in Table 1.

The blasting excavation of underground powerhouse adopts blast hole with the diameter of $\varphi 42 \mathrm{~mm}$ and $2 \#$ rock emulsion explosive with the diameter of $\varphi 25 \mathrm{~mm}$. After 


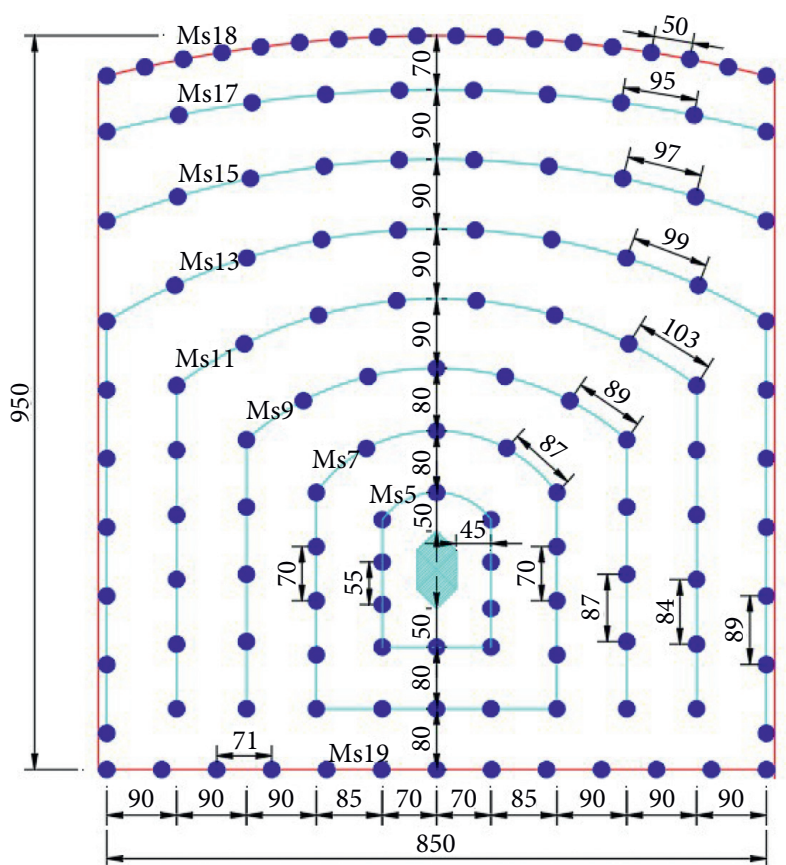

Figure 3: Schematic diagram of the design hole layout of the pilot tunnel blasting in the first floor.

TABLe 1: Detonator delay time parameter.

\begin{tabular}{lccccccccc}
\hline Detonator section & MS5 & MS7 & MS9 & MS11 & MS13 & MS15 & MS17 & MS18 & MS19 \\
\hline Delay time/ms & 50 & 110 & 200 & 310 & 460 & 650 & 880 & 1200 & 1400 \\
\hline
\end{tabular}

equivalent calculation, the average value of explosive density $\rho_{e}$ is $1.0 \mathrm{~g} / \mathrm{cm}^{3}$, and the average value of detonation wave velocity is $3400 \mathrm{~m} / \mathrm{s}$. According to formula (11), it can be calculated that when the main blast hole is detonated, the peak value of explosion load on the wall of the hole is about $119 \mathrm{MPa}$. The resulting equivalent triangle explosion pressure is shown in Figure 4.

\section{Numerical Simulation Calculation of Cumulative Damage of Concrete}

3.1. Calculation Location. The underground powerhouse of the Qingyuan Pumped Storage Power Station is composed of three parts: main powerhouse, auxiliary powerhouse, and installation yard. The excavation size is $169.5 \mathrm{~m} \times 25.5 \mathrm{~m} \times$ $55.7 \mathrm{~m}$. The rock anchor beam is set on the upstream and downstream side walls of the first floor of the main powerhouse. Each side wall has a total length of $143.5 \mathrm{~m}$. The horizontal width of the excavated rock platform is $0.5 \mathrm{~m}$. After the concrete is cast, it is $1.6 \mathrm{~m}$ wide and $2.9 \mathrm{~m}$ high, as shown in Figure 5.

In order to study the effect of blasting excavation of the underground powerhouse on the cumulative damage of the concrete supporting structure, the excavation process of the third floor of the underground powerhouse is selected as the research object, and the application processes of five equivalent blasting loads are analyzed. This research work mainly considers three situations of 7 days, 28 days, and 14 days after the completion of concrete pouring of the rock

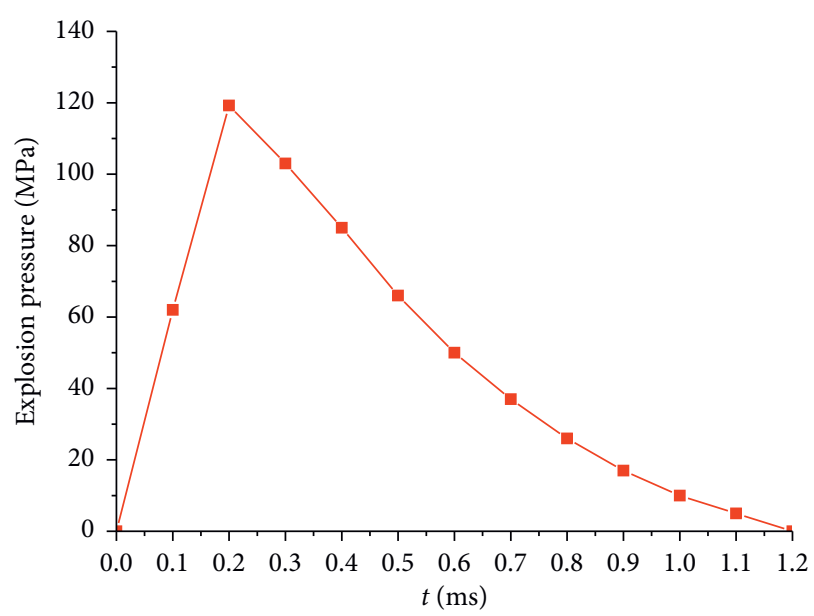

FIgURE 4: Equivalent triangle explosion pressure of the underground powerhouse (unit: $\mathrm{cm}$ ).

anchor beam, which is defined as working condition 1, working condition 2 , and working condition 3 , respectively.

3.2. Calculation Model. The ANSYS/LS-DYNA program was used to conduct a numerical simulation study on the blasting excavation process of the underground powerhouse [20,21], and the cumulative damage effects of the blasting times and the blasting center distance on the rock anchor beam supporting structure were analyzed. The restart method is 


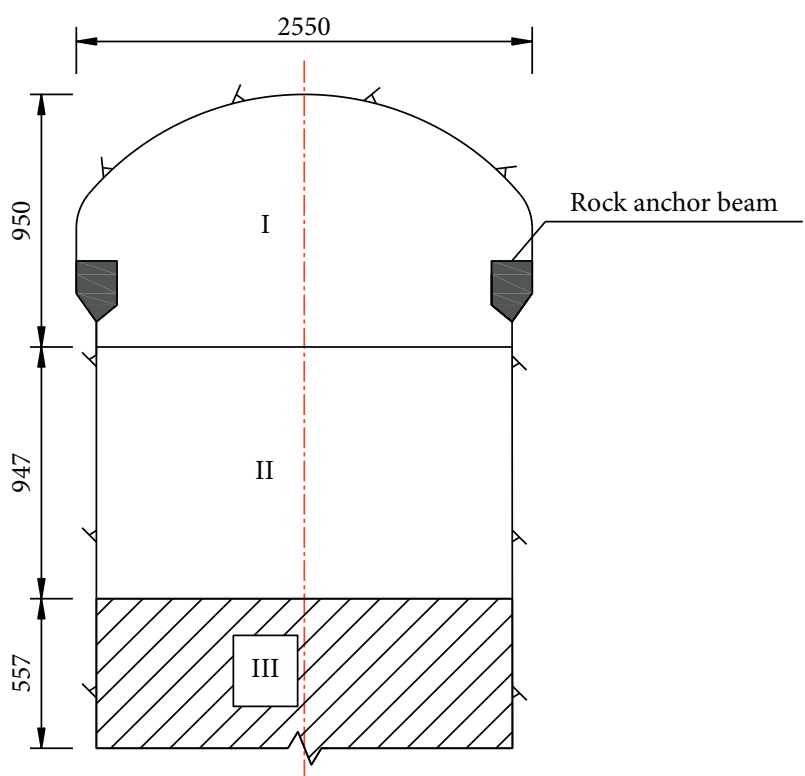

FIGURE 5: Layered excavation of underground powerhouse (unit: $\mathrm{cm})$.

used for numerical calculation [22]. Considering the influence of symmetry and boundary conditions, 1/4 of the actual size is selected to establish the numerical model [23-26]. The size of this modeling is $33.25 \mathrm{~m} \times 20 \mathrm{~m} \times 67.2 \mathrm{~m}$ (length $\times$ width $\times$ height). The model boundary and the finite unit model are shown in Figure 6. The RHT constitutive model is embedded in the numerical calculation model, and the relevant rock and concrete material parameters are obtained based on experimental value of the field test as shown in Table 2.

Considering the full-section blasting excavation process of the first 5 sections of the third floor of the powerhouse, the cumulative damage effects of surrounding rock and rock anchor beam concrete under 5 blasting loads are calculated, and the damage condition of rock anchor beam caused by blasting times and blasting center distance is calculated by regression. Figure 7 shows the schematic diagram of the monitoring points design of rock anchor beam concrete.

\subsection{Analysis of Cumulative Damage of Rock Anchor Beam Concrete}

3.3.1. Working Condition 1. The cumulative damage change process of rock anchor beam concrete obtained by numerical simulation calculation is shown in Figure 8. It can be seen from the cumulative damage nephogram of the blasting that the full-section blasting excavation of the third floor of the powerhouse will be started 7 days after the completion of the concrete pouring of rock anchor beam.

The cumulative damage of the solid unit corresponding to the rock anchor beam under blasting is shown in Figures 9 and 10. The lower part of the rock anchor beam is damaged in a large range under the first blasting action, and under the second blasting action, the rock anchor beam has a continuous and extensive damage. With the increase of blasting times, the cumulative damage of the rock anchor beam gradually expands, and by the fifth blasting, most of rock anchor beam units are damaged. The monitoring points of the solid unit corresponding to the parts of the rock anchor beam are extracted for analysis.

3.3.2. Working Condition 2. The process of cumulative damage change of rock anchor beam concrete is obtained through numerical simulation calculation. It can be seen from Figure 11 that when the full-section blasting excavation of the third floor of the powerhouse is carried out 28 days after the completion of the concrete pouring of the rock anchor beam, the entire rock anchor beam unit does not produce large damage and destruction under the action of 5 times of repeated blasting, and only a few units produced local damage under the action of reflected stress waves. It shows that at this time, the concrete has reached sufficient strength, and the blasting excavation will not have a significant impact on it.

By analyzing the monitoring points of the solid units corresponding to the rock anchor beams (Figures 12 and 13), it can be seen that only the $P_{1}$ and $Q_{1}$ of the extracted relevant monitoring points have been damaged, while the damage values of other units along or perpendicular to the axis of the powerhouse all less than 1 . With the increase of blasting times, the cumulative damage does not increase gradually.

3.3.3. Working Condition 3. The process of cumulative damage change of rock anchor beam concrete is obtained through numerical simulation calculation. It can be seen from Figure 14 that when the full-section blasting excavation of the third floor of the powerhouse is carried out 14 days after the completion of the concrete pouring of the rock anchor beam, some units in the lower area of the rock anchor beam are damaged. With the increase of the blast times, the cumulative damage of the entire rock anchor beam is centered on the location of the blast source and gradually expands along and perpendicular to the axis of the powerhouse, and the cumulative damage gradually increases. As shown in Figures 15 and 16, the exposed surface of the upper part of the third floor of the powerhouse is closer to the rock anchor beam, and the length of the rock anchor beam along the axis of the powerhouse is much greater than the height perpendicular to the axis of the powerhouse. Therefore, under the action of multiple blasts, the cumulative damage of the rock anchor beam perpendicular to the axis of the powerhouse is greater than that along the axis of the powerhouse.

\section{The Relationship between Cumulative Damage and Blasting Times and Blast Center Distance}

\subsection{Relationship between Cumulative Damage and Blasting Times}

4.1.1. Cumulative Damage Analysis of Concrete along the Axis of Powerhouse. This time, the blasting excavation of the third floor of the underground powerhouse 14 days after the 


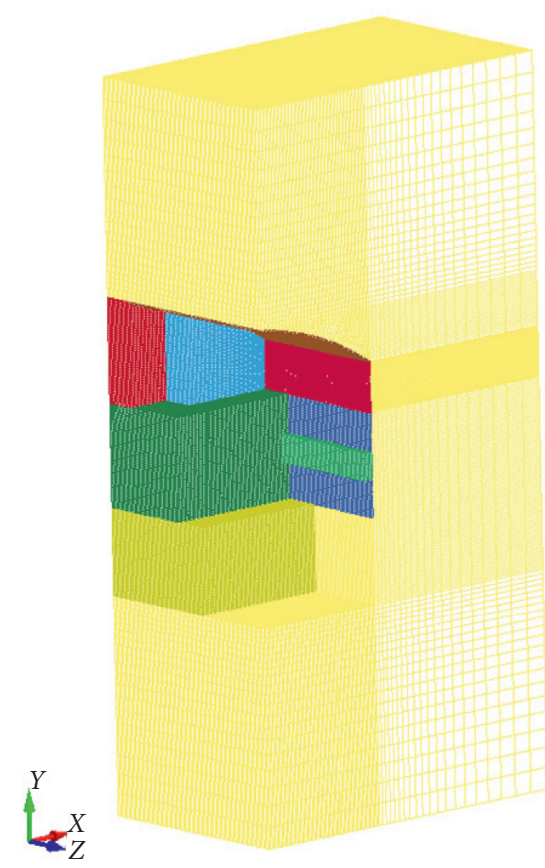

(a)

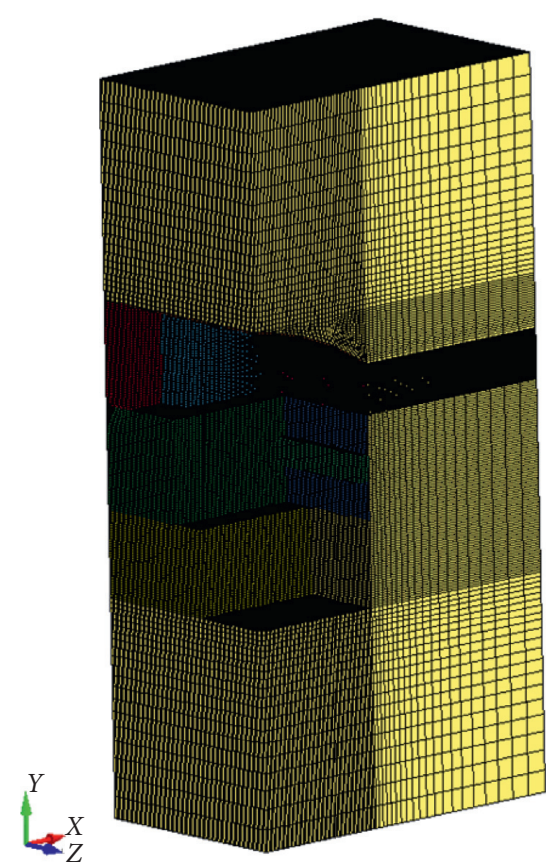

(b)

Figure 6: Finite unit model diagram. (a) Perspective view of finite unit model network. (b) Finite unit model.

TABLe 2: Parameters of the RHT concrete model.

\begin{tabular}{lccc}
\hline Parameter & Value & Parameter & Value \\
\hline Material density $\rho_{0}$ & $1780 \mathrm{~kg} / \mathrm{m}^{3}$ & Failure surface parameters $A$ & 1.6 \\
Initial porosity $\alpha_{0}$ & 1.1613 & Failure surface index $n$ & 0.55 \\
Pressure at the beginning of pore crushing $p_{\mathrm{el}}$ & $18.5 \mathrm{MPa}$ & Tension compression meridian ratio parameter $Q_{\mathrm{O}}$ & 0.68 \\
Pressure at pore is fully compacted $p_{\text {comp }}$ & $0.556 \mathrm{GPa}$ & Rhode angle correlation coefficient $B$ & 0.08 \\
Porosity index $N$ & 2.0 & Shrinkage strain rate index $c$ & 0.032 \\
Hugoniot coefficient $A_{1}$ & $39.75 \mathrm{GPa}$ & Tensile strain rate index $t$ & 0.036 \\
State equation parameters $B_{1}$ & 1.306 & Residual stress intensity $A_{f}$ & 2.42 \\
Shear modulus $G$ & $12.0 \mathrm{GPa}$ & Initial damage parameters $D_{1}$ & 0.052 \\
\hline
\end{tabular}

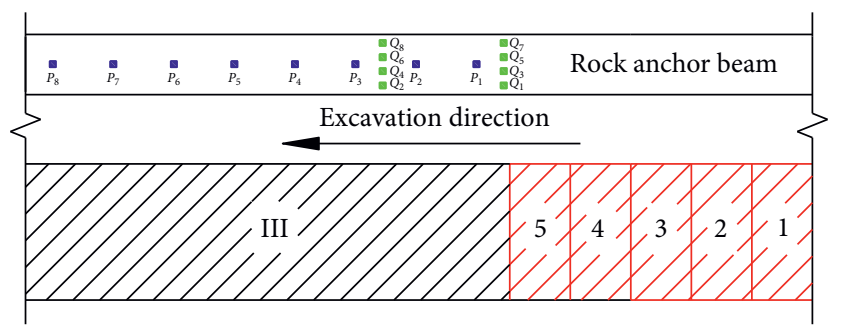

FIGURE 7: Schematic diagram of the monitoring point design of rock anchor beam concrete.

completion of the concrete pouring of the rock anchor beam was taken as the analysis object. Deducing the damage value of the monitoring point of the cumulative damage of the rock anchor beam along the axis of the powerhouse, the relationship between the damage value and blasting times can be obtained. As shown in Figure 17, the monitoring points along the axis of powerhouse are $R_{1}, R_{2}, R_{3}, R_{4}, R_{5}$, and $R_{6}$, and their distances from the tunnel face are $0.2 \mathrm{~m}$,
$1.2 \mathrm{~m}, 2.2 \mathrm{~m}, 3.2 \mathrm{~m}, 4.2 \mathrm{~m}$, and $5.2 \mathrm{~m}$, respectively. The curve relationship between the damage value of each unit and blasting times is shown in Figure 18.

It can be seen from Figure 18 that the damage of rock mass shows a nonlinear increasing characteristic with the increase of the blasting times. According to the nonlinear characteristics of blasting damage evolution of rock anchor beam, a polynomial relationship is used for curve regression analysis, and the polynomial is obtained as follows:

$$
y=A_{0}+A_{1} x+A_{2} x^{2}+A_{3} x^{3},
$$

where $y$ is the blasting damage value of rock mass. $x$ is the blasting times. $A_{0}, A_{1}, A_{2}$, and $A_{3}$ are undetermined constants.

Through the regression calculation and analysis, the polynomial regression equation between unit blasting damage and blasting times is shown in Table 3, and the confidence levels are all greater than 0.98 . It is indicated that the relationship between blasting damage of rock anchor beam and blasting times conforms to the cubic polynomial 


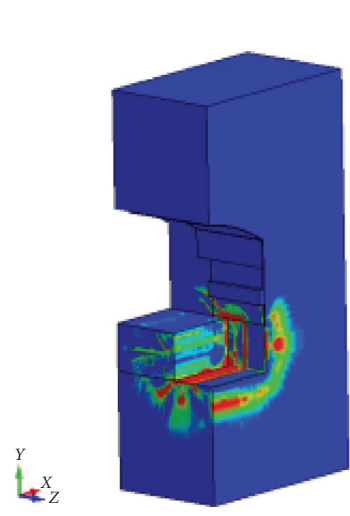

(a)
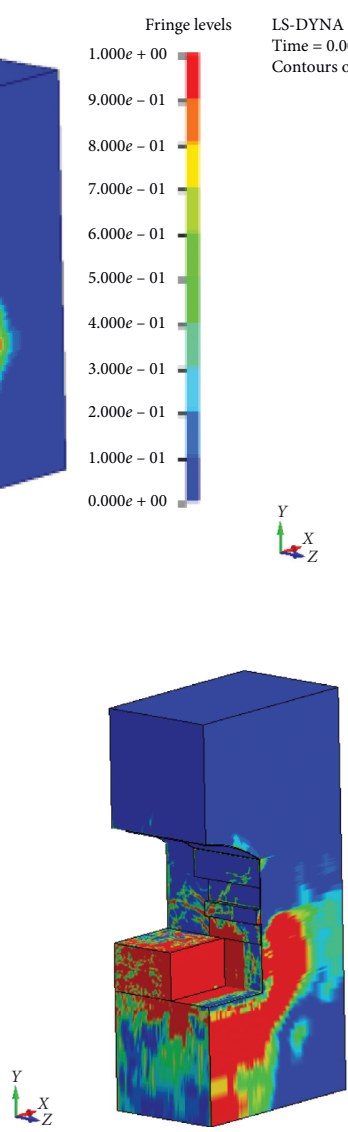

(d)

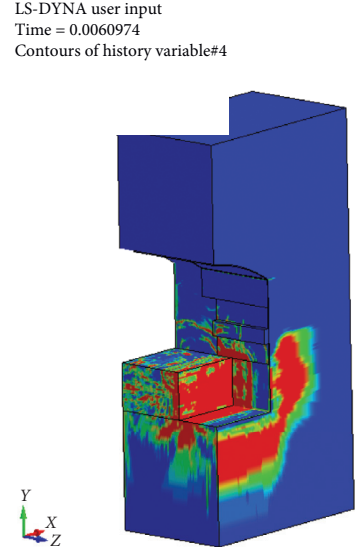

(b)
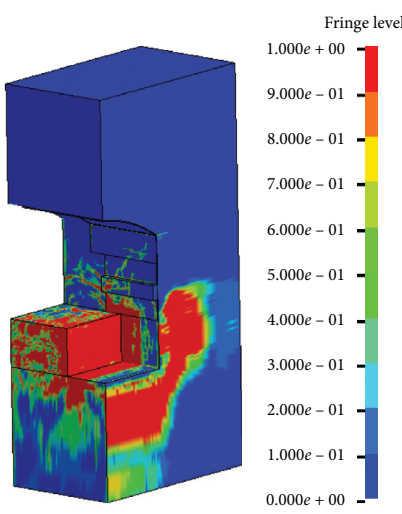

(c)

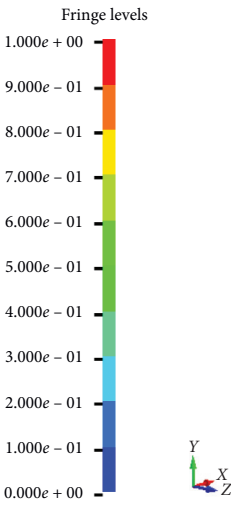

$\alpha_{Z}^{X}$
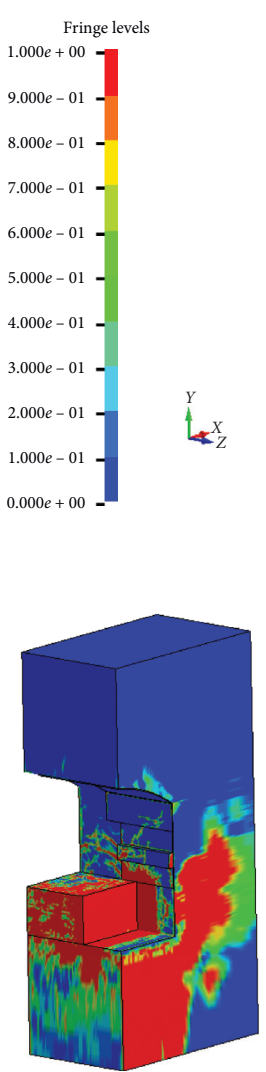

(e)

FIGURE 8: Cumulative damage nephogram of surrounding rock and rock anchor beam concrete under blasting. (a) $3.1 \mathrm{~ms}$, (b) $6.1 \mathrm{~ms}$, (c) $9.1 \mathrm{~ms}$, (d) $12.1 \mathrm{~ms}$, and (e) $15.0 \mathrm{~ms}$.

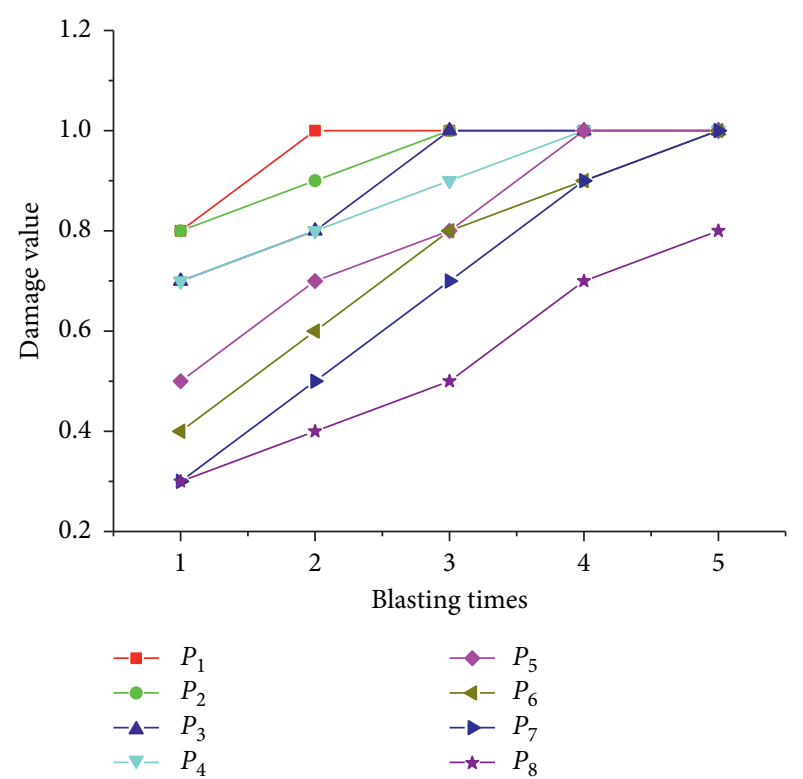

Figure 9: The curve of the relationship between cumulative damage of rock anchor beam monitoring points along the axis of powerhouse and blasting times.

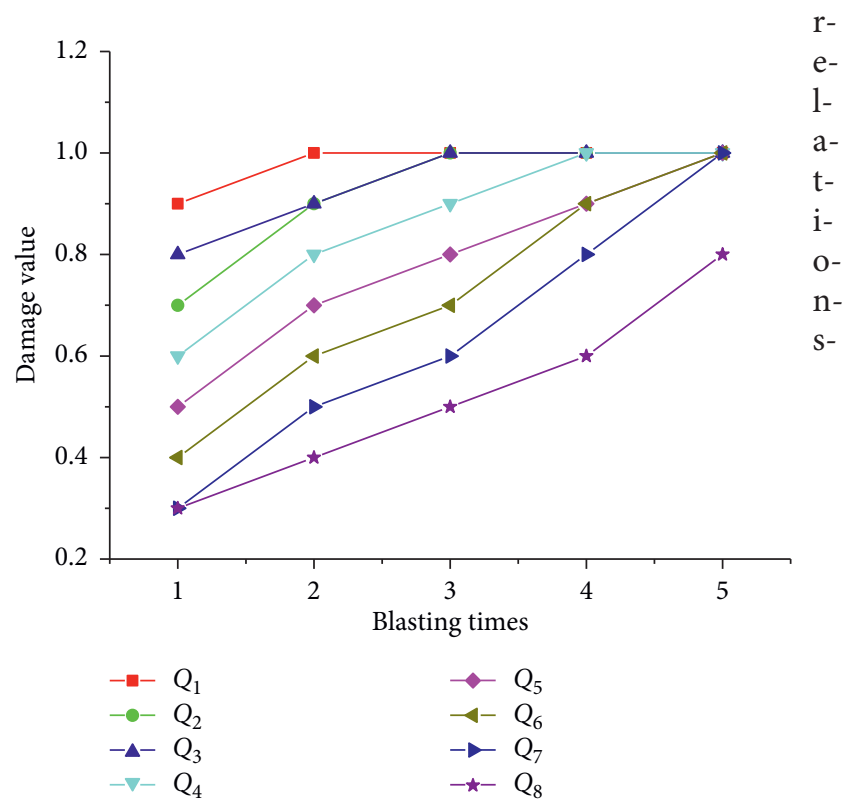

Figure 10: The curve of the relationship between cumulative damage of rock anchor beam monitoring points perpendicular to the axis of powerhouse and blasting times. 


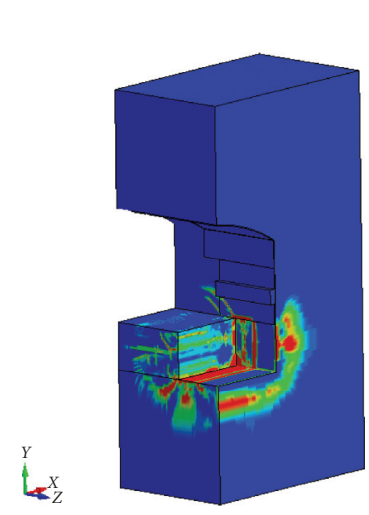

(a)
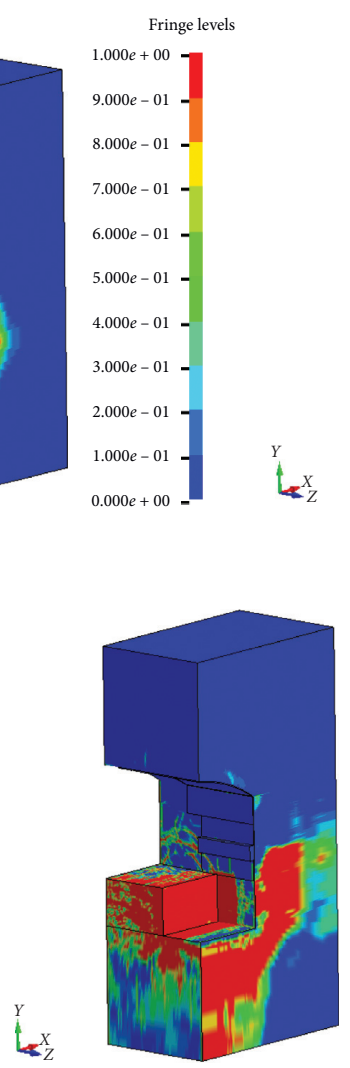

(d)

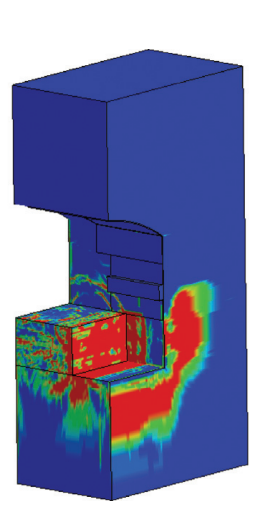

(b)

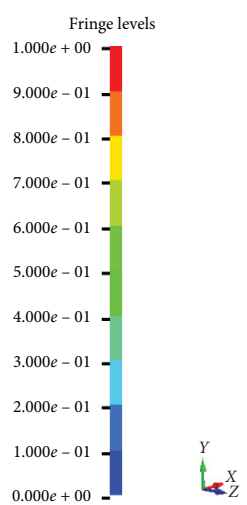

$\operatorname{Lic}_{Z}^{X}$

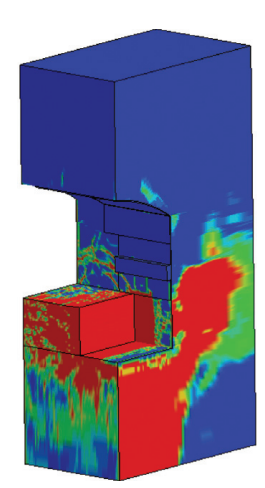

(e)
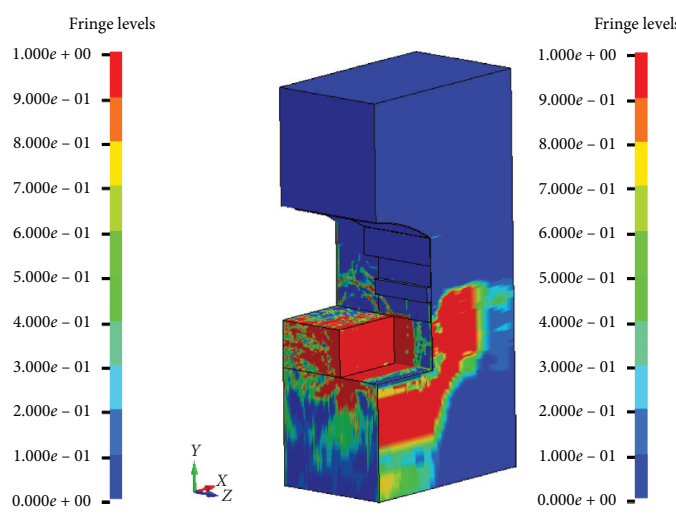

(c)

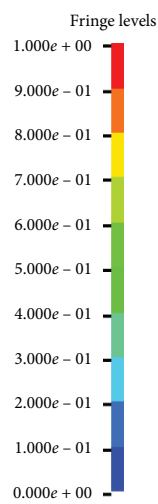

FiguRE 11: Cumulative damage nephogram of surrounding rock and rock anchor beam concrete under blasting. (a) $3.1 \mathrm{~ms}$, (b) $6.1 \mathrm{~ms}$, (c) $9.1 \mathrm{~ms}$, (d) $12.1 \mathrm{~ms}$, and (e) $15.0 \mathrm{~ms}$.

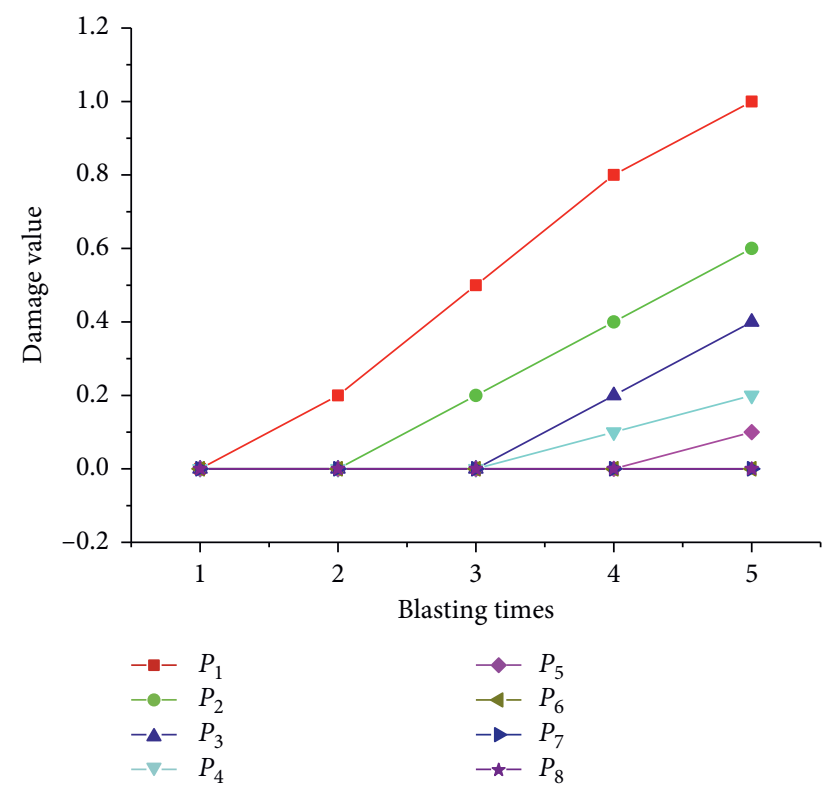

FIgURE 12: The curve of the relationship between cumulative damage of rock anchor beam monitoring points along the axis of powerhouse and blasting times.

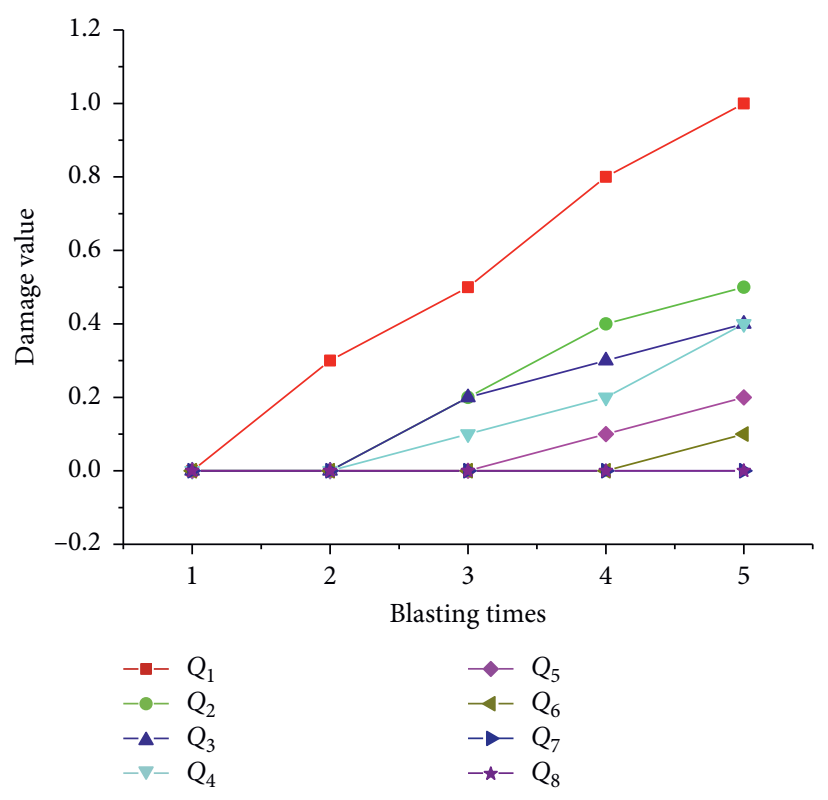

FIGURE 13: The curve of the relationship between cumulative damage of rock anchor beam monitoring points perpendicular to the axis of powerhouse and blasting times. 


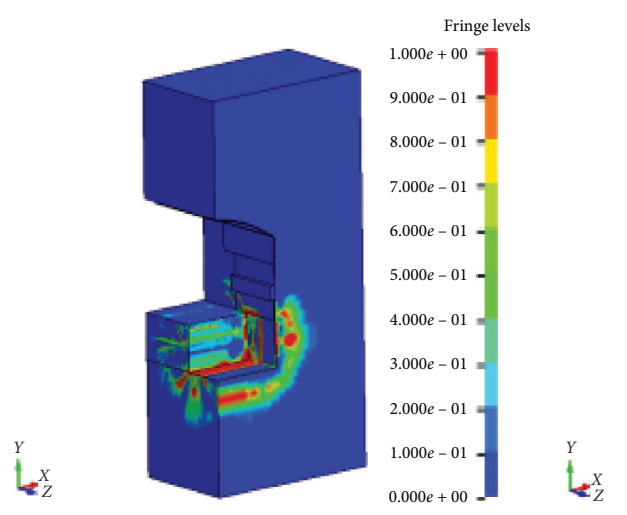

(a)

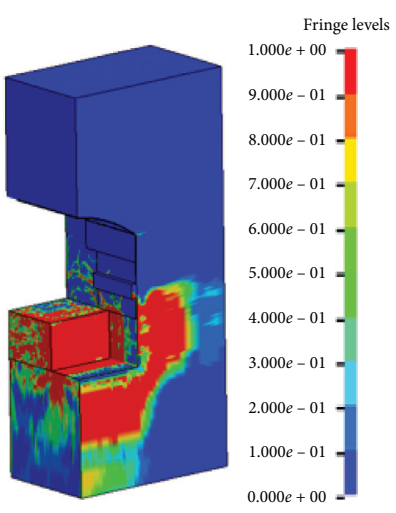

(c)

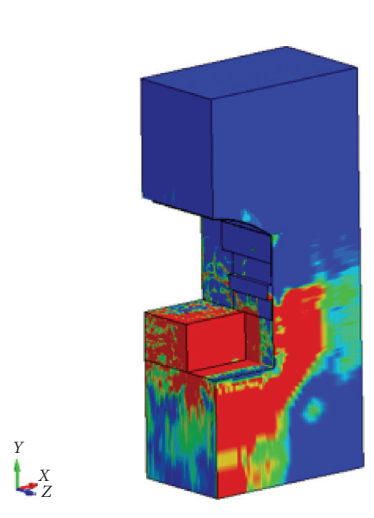

(d)

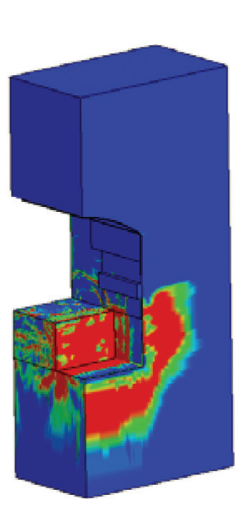

(b)

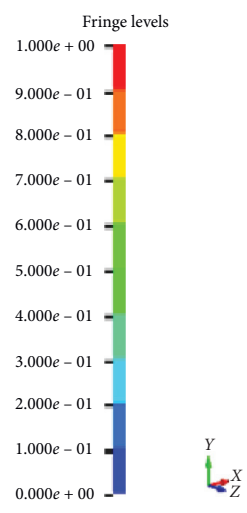

LS-DYNA user input

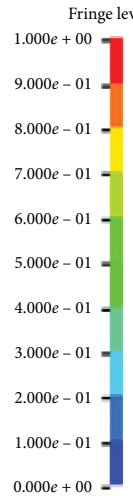

$L_{Z}^{Y}$

Time $=0.0150010$

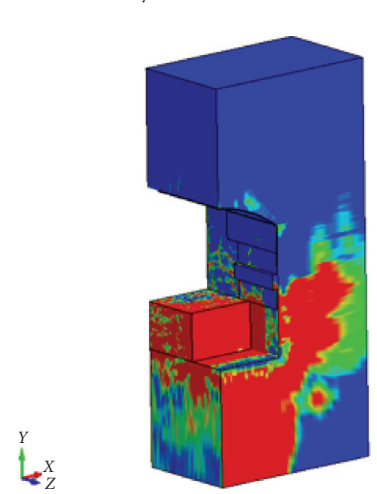

(e)

FIGURE 14: Cumulative damage nephogram of surrounding rock and rock anchor beam concrete under blasting. (a) $3.1 \mathrm{~ms}$, (b) $6.1 \mathrm{~ms}$, (c) $9.1 \mathrm{~ms}$, (d) $12.1 \mathrm{~ms}$, and (e) $15.0 \mathrm{~ms}$.

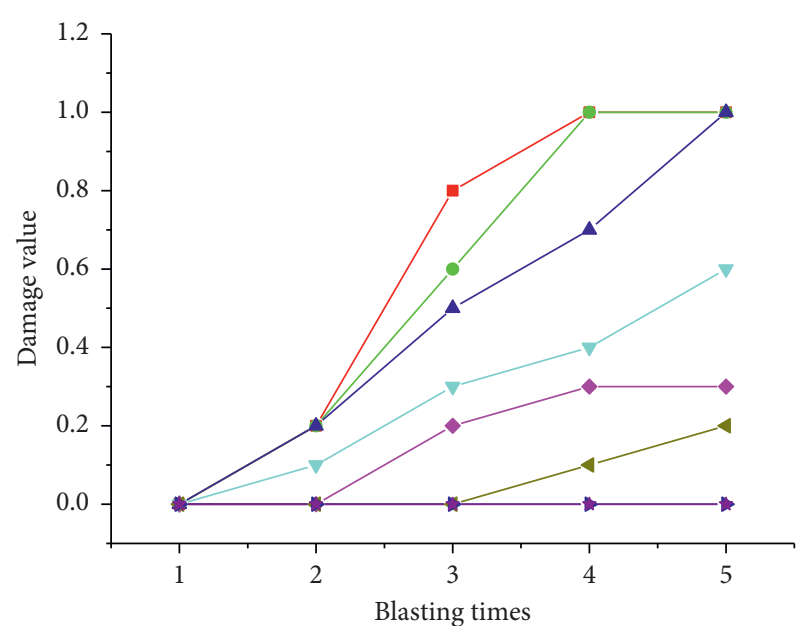

$$
\begin{array}{ll}
-\varpi P_{1} & --P_{5} \\
-\bullet-P_{2} & --P_{6} \\
-\triangle-P_{3} & \\
-\nabla-P_{4} & -P_{7} \\
\hline
\end{array}
$$

FIgURE 15: The curve of the relationship between cumulative damage of rock anchor beam monitoring points along the axis of powerhouse and blasting times.

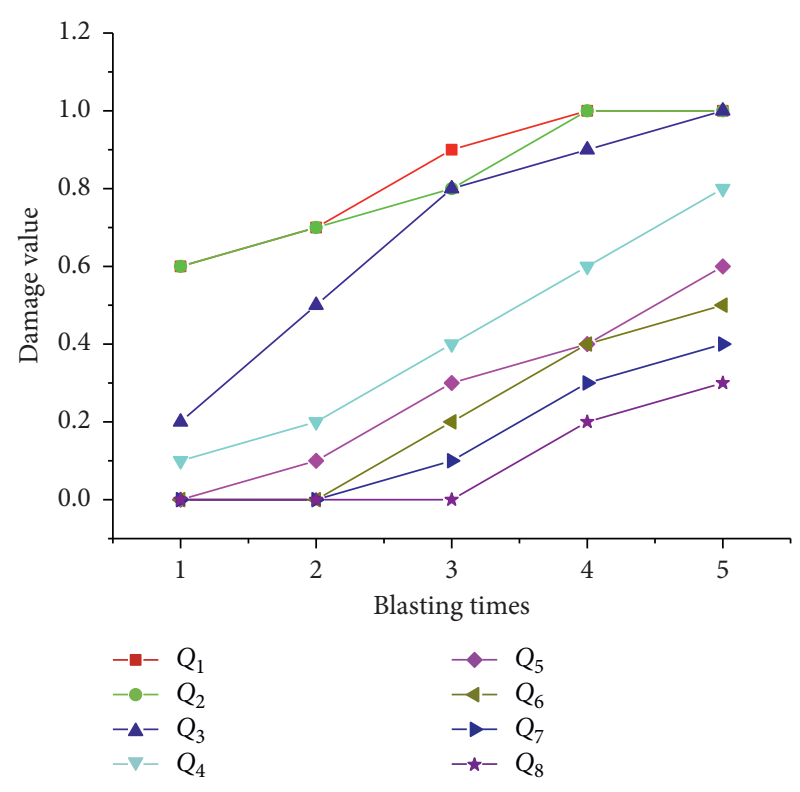

FIGURE 16: The curve of the relationship between cumulative damage of rock anchor beam monitoring points perpendicular to the axis of powerhouse and blasting times. 


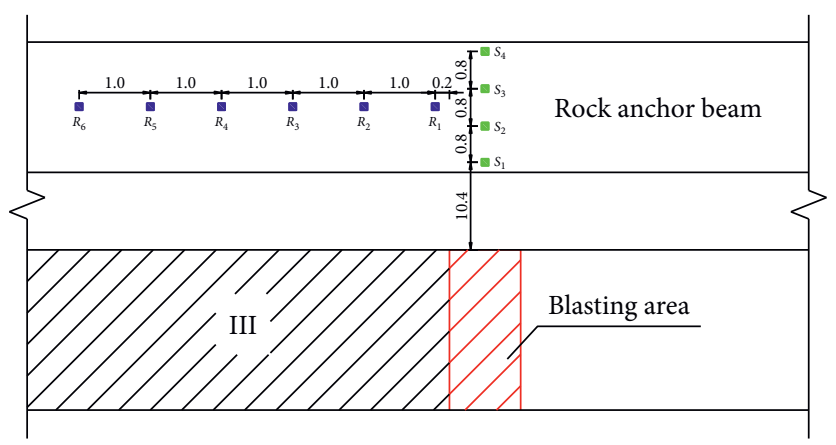

FIgURE 17: The monitoring points of rock anchor beam concrete (unit: $\mathrm{m}$ ).

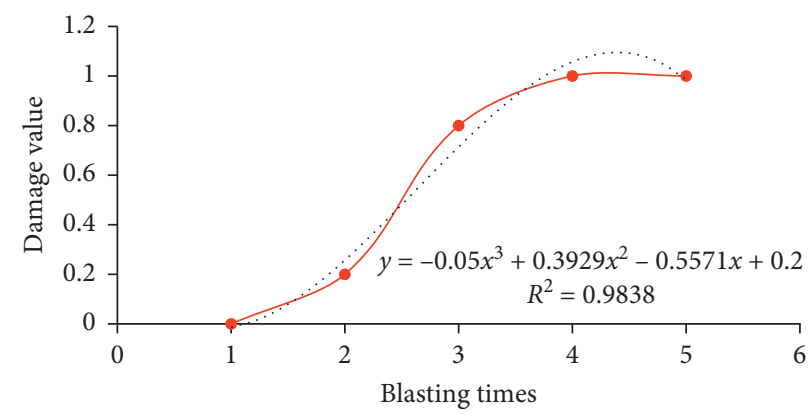

FIGURE 18: The regression relationship between the blasting damage value of $R_{1}$ and blasting times.

TABLE 3: The relationship between the damage value of some unit monitoring points of the rock anchor beam along the axis of the powerhouse and blasting times.

\begin{tabular}{lcc}
\hline Monitoring points & Regression analysis & Confidence level \\
\hline$R_{1}$ & Relationship between damage value $(y)$ and blasting times $(x)$ & 0.9838 \\
$R_{2}$ & $y=-0.05 x^{3}+0.3929 x^{2}-0.5571 x+0.2$ & 0.9993 \\
$R_{3}$ & $y=-0.05 x^{3}+0.4214 x^{2}-0.7286 x+0.36$ & 0.9964 \\
$R_{4}$ & $y=-0.04 x^{3}+0.0071 x^{2}+0.2071 x-0.22$ & 0.9874 \\
$R_{5}$ & $y=-0.0058 x^{3}+0.0617 x^{2}-0.0457 x$ & 0.9860 \\
$R_{6}$ & $y=-0.025 x^{3}+0.2179 x^{2}-0.4571 x+0.26$ & 0.9821 \\
\hline
\end{tabular}

hip. The damage range of rock anchor beam along the axis of powerhouse is about $2.2 \mathrm{~m}-3.2 \mathrm{~m}$.

4.1.2. Cumulative Damage Analysis of Concrete Perpendicular to the Axis of Powerhouse. By deriving the damage value of the cumulative damage monitoring point of the rock anchor beam perpendicular to the axis of the powerhouse, the relationship between the damage value and the blasting times can be obtained. The monitoring points perpendicular to the axis of the powerhouse are $S_{1}, S_{2}, S_{3}$, and $S_{4}$, and their distances from the tunnel face are $10.4 \mathrm{~m}, 11.2 \mathrm{~m}, 12.0 \mathrm{~m}$, and $12.8 \mathrm{~m}$, respectively. The curve relationship between the damage value of each unit and blasting times is shown in Figure 19.

Through regression calculation and analysis, the polynomial regression equation between unit blasting damage and blasting times is shown in Table 4, and the confidence levels are all greater than 0.98 . It is indicated that the relationship between blasting damage of rock anchor beams and blasting times conforms to the cubic polynomial relationship. In this simulation calculation, the height of the rock anchor beam perpendicular to the axis of the powerhouse is limited, and under the action of 5 times of blasting, damage and destruction are eventually generated.

\subsection{Relationship between Cumulative Damage and Blast Center Distance}

4.2.1. Cumulative Damage Analysis of Rock Anchor Beam Concrete along the Axis of the Powerhouse. The cumulative damage data of the rock anchor beam concrete along the axis of the powerhouse are derived to analyze the evolution law of rock anchor beam damage with the increase of the blast times. The variation law of the cumulative damage of the rock anchor beam along the axis of the powerhouse with the blast center distance is shown in Figure 20.

According to the analysis of the change rules, it is concluded that with the increase of the blast center distance, 


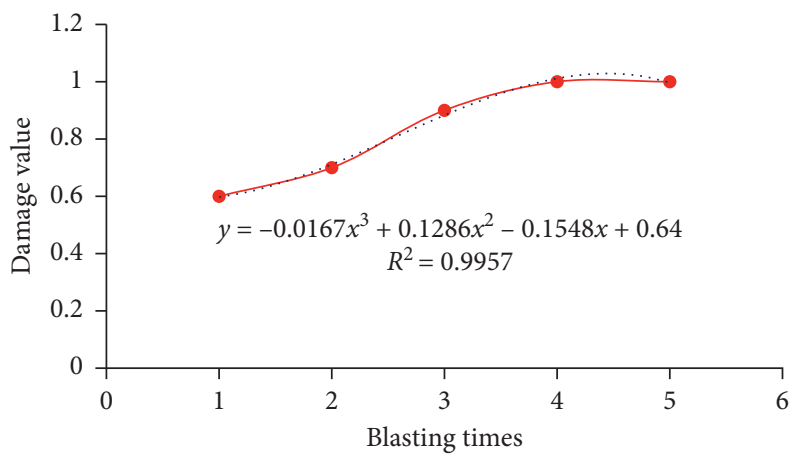

FigURE 19: Regression relationship between the blasting damage value of $S_{1}$ and the blasting times.

TABLE 4: Relationship between the damage value of some unit monitoring points of rock anchor beams perpendicular to the axis of the powerhouse and the blasting times.

\begin{tabular}{lcc}
\hline Monitoring points & Regression analysis & Confidence level \\
\hline$S_{1}$ & Relationship between damage value $(y)$ and blasting times $(x)$ & 0.9957 \\
$S_{2}$ & $y=-0.0167 x^{3}+0.1286 x^{2}-0.1548 x+0.64$ & 0.9846 \\
$S_{3}$ & $y=-0.05 x^{3}+0.4143 x^{2}-0.7357 x+0.56$ & 0.9994 \\
$S_{4}$ & $y=-0.0667 x^{3}+0.5786 x^{2}-1.1548 x+0.64$ & 0.9885 \\
\hline
\end{tabular}

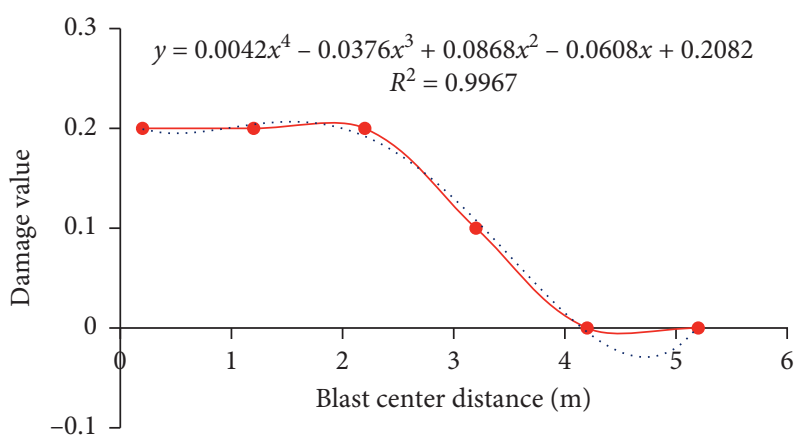

Figure 20: The variation law of cumulative damage of rock anchor beam along the axis of the powerhouse with the blast center distance (the $2^{\text {nd }}$ blast).

the degree of blasting damage of the rock anchor beam gradually decreases. The unit closest to the blast source has the greatest degree of blasting damage. The size of the blast center distance also has a significant effect on the cumulative growth curve of blasting damage. The closer the unit is to the blast source, the more obvious the nonlinear characteristic of the damage curve is, and vice versa. The damage of the rock anchor beam shows a nonlinear decreasing characteristic with the increase of the blast center distance. After fitting analysis, this nonlinear decreasing relationship between the damage of the rock anchor beam and blast center distance is as follows:

$$
y=A_{0}+A_{l} x+A_{2} x^{2}+A_{3} x^{3}+A_{4} x^{4}
$$

where $y$ is the blasting damage value of rock mass. $x$ is the blast center distance. $A_{0}, A_{1}, A_{2}, A_{3}$, and $A_{4}$ are undetermined constants.
Through regression calculation and analysis, the polynomial regression equation between blasting damage and blast center distance is shown in Table 5, and the confidence levels are all greater than 0.98 . It shows that the relationship between the blasting damage value of the rock anchor beam and the blast center distance conforms to the quartic polynomial relationship.

4.2.2. Cumulative Damage Analysis of Concrete Perpendicular to the Axis of the Powerhouse

The cumulative damage data of the rock anchor beam perpendicular to the axis of the powerhouse are derived to analyze the evolution law of the rock anchor beam damage with the increase of the blast center distance. The variation law of the cumulative damage of the rock anchor beam perpendicular to the axis of the powerhouse with the blast center distance is shown in Figure 21.

According to the analysis of the 5 times of change rules, the nonlinear decreasing relationship between the rock 
TABLE 5: The relationship between the damage value of some unit monitoring points of the rock anchor beam along the axis of the powerhouse and the blast center distance.

\begin{tabular}{lcc}
\hline Blast times & $\begin{array}{c}\text { Regression analysis } \\
\text { Relationship between damage value }(y) \text { and blast center distance }(x)\end{array}$ & Confidence level \\
\hline $2^{\text {nd }}$ & $y=0.0042 x^{4}-0.0376 x^{3}+0.0868 x^{2}-0.0608 x+0.2082$ & 0.9967 \\
$3^{\text {rd }}$ & $y=0.0115 x^{4}-0.1312 x^{3}+0.502 x^{2}-0.8969 x+1.1599$ & 0.9918 \\
$4^{\text {th }}$ & $y=-0.0044 x^{4}+0.0633 x^{3}-0.3051 x^{2}+0.3053 x+0.955$ & 0.9897 \\
$5^{\text {th }}$ & $y=0.0094 x^{4}-0.0849 x^{3}+0.1634 x^{2}-0.0732 x+1.004$ & 0.9932 \\
\hline
\end{tabular}

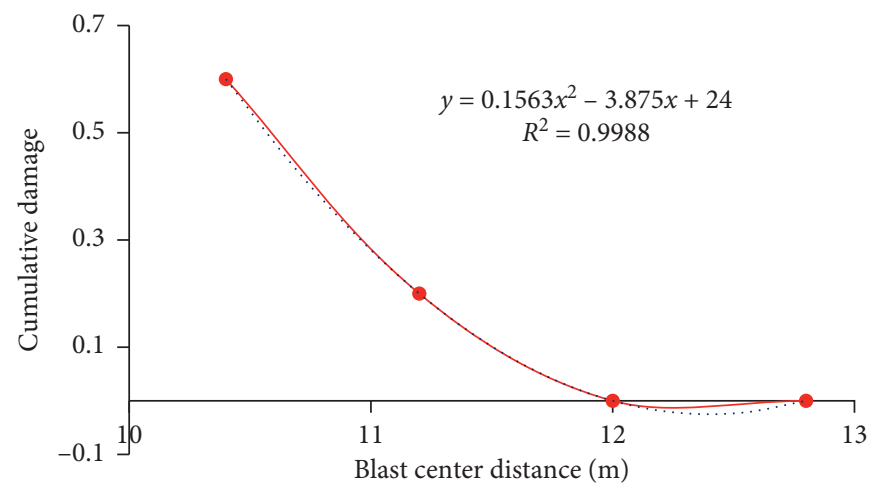

FIGURE 21: The variation law of cumulative damage of rock anchor beam concrete perpendicular to the axis of the powerhouse with the blast center distance (the $2^{\text {nd }}$ blast).

TABle 6: The relationship between the damage value of some unit monitoring points of the rock anchor beam along the axis of the powerhouse and the blast center distance.

\begin{tabular}{lcc}
\hline Blast times & Regression analysis & Confidence level \\
& Relationship between damage value $(y)$ and blast center distance $(x)$ & 1 \\
$2^{\text {nd }}$ & $y=0.1563 x^{2}-3.875 x+24$ & 0.9947 \\
$3^{\text {rd }}$ & $y=0.1563 x^{2}-3.95 x+24.97$ & 0.9987 \\
$4^{\text {th }}$ & $y=0.1172 x^{2}-3.0563 x+20.015$ & 0.9986 \\
$5^{\text {th }}$ & $y=0.0391 x^{2}-1.2438 x+9.715$ & \\
\hline
\end{tabular}

anchor beam damage and the blast center distance is as follows:

$$
y=A_{0}+A_{1} x+A_{2} x^{2}
$$

where $y$ is the blasting damage value of rock mass. $x$ is the blast center distance. $A_{0}, A_{1}$, and $A_{2}$ are undetermined constants.

Through regression calculation and analysis, the polynomial regression equation between blasting damage and blast center distance is shown in Table 6, and the confidence levels are all greater than 0.99 . It shows that the relationship between the blast damage of the rock anchor beam and the blast center distance conforms to the quadratic polynomial.

\section{Conclusion}

Through the numerical simulation study on the cumulative damage growth law of rock anchor beam concrete under multiple blasting, the functional relations between the $\mathrm{cu}$ mulative damage degree of rock anchor beam concrete under the action of blasting dynamic load and the blast times and the blast center distance are obtained:
(1) When the full-section blasting excavation of the third floor of the powerhouse is completed, the damage range of the rock anchor beam concrete along the axis of the powerhouse is about $2.2 \mathrm{~m}-3.2 \mathrm{~m}$. Due to the limited height of rock anchor beam concrete perpendicular to the axis of the powerhouse, under the action of 5 times of blasting dynamic load, the damage and destruction are eventually produced.

(2) 7 days after the completion of the concrete pouring of the rock anchor beam, damage and destruction effects are produced under a single blasting action, indicating that no blasting activities are allowed. 28 days after the completion of the concrete pouring of the rock anchor beam, there is basically no damage and destruction under multiple blasting, indicating that the current blasting conditions will not have a significant impact on the rock anchor beam concrete.

(3) 14 days after the completion of the concrete pouring of the rock anchor beam, the growth process of the cumulative damage effect of the rock anchor beam concrete structure under the disturbance of the 
blasting excavation of the underground powerhouse has obvious nonlinear characteristics. With the increase of the number of blasting, it shows a nonlinear increasing characteristic, and with the increase of the blasting center distance, it shows a nonlinear decreasing characteristic.

(4) The relationships between cumulative damage of rock anchor beam along and perpendicular to the axis of powerhouse and blasting times are in accordance with the cubic polynomials. The relationships between the cumulative damage of rock anchor beam along and perpendicular to the axis of powerhouse and blast center distance are in accordance with the quartic polynomial and quadratic polynomial.

\section{Data Availability}

The curve data used to support the findings of this study are available from the corresponding author upon request.

\section{Conflicts of Interest}

The authors declare that they have no conflicts of interest.

\section{Acknowledgments}

This work was supported by the Fundamental Research Funds for the National Natural Science Foundation of China (51774222, 51779197, and 51979208), the Postdoctoral Innovation Research Post of Hubei Province of China (20201jb001), the Hubei Key Laboratory of Roadway Bridge and Structure Engineering (Wuhan University of Technology) (no. DQJJ201904), the Fundamental Research Funds for the Central Universities (WUT: 2019IVA098), and the Youth Talent Project of Science and Technology Research Program of Hubei Provincial Department of Education (Q20192801).

\section{References}

[1] R. Lien, J. Kristiansen, and L. S. Pran, "Suspended support for crane rails in Norwegian underground power-houses," International Water Power and Dam Construction, vol. 42, no. 4, pp. 48-50, 1990.

[2] R. D. Gill and D. S. Lawrenson, "Underground works at Kenya's kiambere project," International Water Power and Dam Construction, vol. 38, no. 5, pp. 13-16, 1986.

[3] X. P. Li, J. H. Huang, Y Luo et al., "Numerical simulation of blast vibration and crack forming effect of rock-anchored beam excavation in deep underground caverns," Shock and Vibration, vol. 2017, Article ID 1812080, 13 pages, 2017.

[4] X. P. Li, J. L. Lv, Y. Luo, and T. T. Liu, "Mechanism study on elevation effect of blast wave propagation in high side wall of deep underground powerhouse," Shock and Vibration, vol. 2018, Article ID 4951948, 15 pages, 2018.

[5] L. X. Xie, W. B. Lu, Q. B. Zhang, Q. H. Jiang, G. H. Wang, and J. Zhao, "Damage evolution mechanisms of rock in deep tunnels induced by cut blasting," Tunnelling and Underground Space Technology, vol. 58, pp. 257-270, 2016.
[6] K. Manoj and S. Mahdi, "A dimensional analysis approach to study blast-induced ground vibration," Rock Mechanics and Rock Engineering, vol. 48, no. 2, pp. 727-735, 2015.

[7] S. Li, X.-T. Feng, Z. Li, B. Chen, C. Zhang, and H. Zhou, "In situ monitoring of rockburst nucleation and evolution in the deeply buried tunnels of Jinping II hydropower station," Engineering Geology, vol. 137-138, pp. 85-96, 2012.

[8] G. Liu, X.-T. Feng, Q. Jiang, Z. Yao, and S. Li, "In situ observation of spalling process of intact rock mass at large cavern excavation," Engineering Geology, vol. 226, pp. 52-69, 2017.

[9] S. Y. Wang, S. W. Sloan, D. C. Sheng, and C. A. Tang, "Numerical analysis of the failure process around a circular opening in rock," Computers and Geotechnics, vol. 39, pp. 8-16, 2012.

[10] H. Zhang, L. Chen, S. Chen, J. Sun, and J. Yang, "The spatiotemporal distribution law of microseismic events and rockburst characteristics of the deeply buried tunnel group," Energies, vol. 11, no. 12, p. 3257, 2018.

[11] M. Ramulu, A. K. Chakraborty, and T. G. Sitharam, "Damage assessment of basaltic rock mass due to repeated blasting in a railway tunnelling project - a case study," Tunnelling and Underground Space Technology, vol. 24, no. 2, pp. 208-221, 2009.

[12] J. B. Duan, W. M. Liang, and H. B. Chu, "Analysis on vibration energy characteristics of concrete under multiple blasting," Mining Researth and Development, vol. 38, no. 10, pp. 16-20, 2018.

[13] F. Liu, H. B. Wang, L. Y. Weng, Y. Y. Gan, and D. J. Yue, "Experimental study on damage characteristics of concrete by using wavelet theory," Chinese Journal of Rock Mechanics and Engineering, vol. 24, no. 14, pp. 2581-2587, 2005.

[14] B. Liang, Z. F. Chen, and X. W. Chen, "Damage analysis of concrete subject to explosive loading," Journal of Projectiles and Guides, vol. 3, pp. 104-107, 2006.

[15] F. Miao, Study on the Coupling Effect of Blasting Damage of Concrete Medium and Environmental Factors, China University of science and technology, Taipei, Taiwan, 2009.

[16] W. X. Zhang, Study on Damage Characteristics of Large Underground Powerhouse Induced by Blasting Vibration, University of Science and Technology of China, Hefei, China, 2008.

[17] Q. Yao, X. G. Yang, X. Z. Chen, and H. T. Li, "Numerical simulation of dynamic response of large underground powerhouse subjected to blasting vibration," Journal of Vibration and Shock, vol. 33, no. 6, pp. 66-76, 2014.

[18] M. Geniş, "Assessment of the dynamic stability of the portals of the dorukhan tunnel using numerical analysis," International Journal of Rock Mechanics and Mining Sciences, vol. 47, no. 8, pp. 1231-1241, 2010.

[19] W. Lu, J. Yang, M. Chen, and C. Zhou, “An equivalent method for blasting vibration simulation," Simulation Modelling Practice and Theory, vol. 19, no. 9, pp. 2050-2062, 2011.

[20] J. Zhao, "Damage evolution mechanisms of rock in deep tunnels induced by cut blasting," Tunnelling and Underground Space Technology, vol. 58, pp. 257-270, 2016.

[21] J. Shi, C. W. W. Ng, and Y. Chen, "Three-dimensional numerical parametric study of the influence of basement excavation on existing tunnel," Computers and Geotechnics, vol. 63, pp. 146-158, 2015.

[22] D. Shi, Y. Li, and S. Zhang, The Explicit Dynamic Analysis on the Basis of ANSYS/LS-DYNA 8.1, Tsinghua University Press, Beijing, China, 2004. 
[23] X. M. Sun, C. L. Ye, Y. C Hu et al., "Numerical simulation analysis of rock blasting structure based on ANSYS/LSDYNA," Exploration Engineering, vol. 46, no. 10, pp. 87-93, 2019.

[24] H. L. Sun, The Study of Linear Charge Blasting Seismic Effect Based on Ansys/ls-Dyna Simulation, Chang'an University, Xi'an, China, 2015.

[25] S. L. Zhang, Structural Deformation Analysis of Roadway Excavation and Lining Based on Based on ANSYS/LS-DYNA, Liaoning University of Engineering and Technology, Liaoning, China, 2017.

[26] X. F. Pan and Y. F. Mao, "The numerical simulation of shaft excavation blasting cavity expansion process based on ANSYS/LS-DYNA," Coal Mine Blasting, vol. 4, pp. 19-24, 2014. 